\title{
The potential usefulness of taurine on diabetes mellitus and its complications
}

\author{
Takashi Ito $\cdot$ Stephen W. Schaffer $\cdot$ \\ Junichi Azuma
}

Received: 15 December 2010/Accepted: 4 March 2011/Published online: 25 March 2011

(C) The Author(s) 2011. This article is published with open access at Springerlink.com

\begin{abstract}
Taurine (2-aminoethanesulfonic acid) is a free amino acid found ubiquitously in millimolar concentrations in all mammalian tissues. Taurine exerts a variety of biological actions, including antioxidation, modulation of ion movement, osmoregulation, modulation of neurotransmitters, and conjugation of bile acids, which may maintain physiological homeostasis. Recently, data is accumulating that show the effectiveness of taurine against diabetes mellitus, insulin resistance and its complications, including retinopathy, nephropathy, neuropathy, atherosclerosis and cardiomyopathy, independent of hypoglycemic effect in several animal models. The useful effects appear due to the multiple actions of taurine on cellular functions. This review summarizes the beneficial effects of taurine supplementation on diabetes mellitus and the molecular mechanisms underlying its effectiveness.
\end{abstract}

Keywords Taurine $\cdot$ Diabetic mellitus - Diabetic complications · Obesity $\cdot$ Insulin resistance

\section{Introduction}

Taurine (2-aminoethanesulfonic acid) is widely distributed and is found in millimolar concentration in mammalian tissues. Many evidences support that taurine is a

T. Ito · J. Azuma $(\bowtie)$

Department of Pharmacy, School of Pharmacy, Hyogo University of Health Sciences, 1-3-6 Minatojima, Chuo-ku, Kobe, Hyogo 650-8530, Japan

e-mail: azuma@huhs.ac.jp

S. W. Schaffer

Department of Pharmacology, College of Medicine,

University of South Alabama, Mobile, AL, USA cytoprotective agent in a variety of tissues. Taurine modulates a variety of cellular functions, including antioxidation, modulation of ion movement, osmoregulation, modulation of neurotransmitters and conjugation of bile acids etc. (Huxtable 1992; Satoh 1998; Schaffer et al. 2000; Sjovall 1959). The source of taurine in body is biosynthesis and dietary intake. Taurine is synthesized from methionine and cysteine mainly in the liver. It is well-known that biosynthetic capacity of taurine is very low in human and is absent in cats, while rodents have high synthetic capacity (Hansen 2001). On the other hand, dietary taurine is ingested from meat and sea food. Especially, sea food is rich in taurine. Yamori et al. (2001) demonstrated that urinary taurine excretion as a marker of taurine intake inversely correlated with mortality rate caused by ischemic heart diseases in world wide epidemiological study. Moreover, taurine depletion by taurine-deficient diet in cats causes various pathological conditions, including retinal degeneration, reproductive failure and dilated cardiomyopathy (Hayes et al. 1975; Pion et al. 1987; Sturman 1991). Therefore, taurine seems an essential nutrient and its deficiency may cause various tissue disorders in human. Moreover, treatment of taurine benefits many kinds of pathologies. The accumulating data show the effectiveness of taurine supplementation against both insulin dependent, non-insulin dependent diabetes mellitus and insulin resistance (Franconi et al. 2004, 2006; Hansen 2001; Schaffer et al. 2009). In addition, taurine supplementation is beneficial to diabetic complications, including retinopathy, nephropathy, neuropathy, atherosclerosis and cardiomyopathy. These useful effects appear due to the multiple actions of taurine on cellular functions. This review summarizes the beneficial effects of taurine supplementation on diabetes and the molecular mechanisms underlying the effectiveness. 


\section{The effect of taurine on hyperglycemia in diabetic animal models and its potential mechanisms}

\section{The effect of taurine on type 1 diabetic models}

The effect of taurine administration for type 1 diabetes has been well investigated. Treatment of taurine before diabetic onset suppressed hyperglycemia and lowered plasma glycated hemoglobin, cholesterol and triglyceride in STZinduced type 1 diabetic rats (Alvarado-Vasquez et al. 2003; Tokunaga et al. 1979, 1983). Moreover, taurine reduced plasma lipid peroxidation products induced in type 1 diabetes mellitus. The prevention of hyperglycemia by taurine was also reported in alloxan-induced type 1 diabetic rabbits (Tenner et al. 2003; Winiarska et al. 2009). Importantly, it has been reported that treatment of taurine started from the time-point of diabetic onset failed to improve hyperglycemia in type 1 diabetic animals (Goodman and Shihabi 1990), indicating that lowering effect of taurine on blood glucose level in type 1 models may be due to the protection of beta cells from STZ or alloxan (Chang and Kwon 2000; Gavrovskaya et al. 2008). Interestingly, taurine supplementation from 2 days later of STZ injection prolonged survival in diabetic rats (Di Leo et al. 2004). This observation indicates that taurine may confer the resistance against some stresses induced by hyperglycemia, which may associate with the beneficial role against the complications, as described below.

Non-obese diabetic (NOD) mice genetically develop autoimmune diabetes caused by infiltration of the pancreatic islets by mononuclear leucocytes. Taurine supplementation starting before birth (pregnant mice were received a diet supplemented with taurine) until weaning significantly increased in pancreatic islet mass in NOD mice (Arany et al. 2004), suggesting that taurine alters islet development. Moreover, taurine treatment delayed the onset time of diabetes, and $20 \%$ of treated female mice remained free of diabetes.

The effect of taurine on obese-induced diabetic models

The Otsuka Long-Evans Tokushima Fatty (OLETF) rat is a model of non-insulin dependent diabetes, which exhibits hyperglycemia and insulin resistance and has accumulated abdominal fat as compared to the normal rats. It has been demonstrated that taurine supplementation improved hyperglycemia and insulin resistance in OLETF rats (Harada et al. 2004; Nakaya et al. 2000). Taurine also suppressed the increase in serum triglyceride and cholesterol, but not body weight and abdominal fat mass. Whereas it was expected that taurine could enhance the calorie consumption and/or lipid oxidation, taurine supplementation did not increase but decrease the energy expenditure and did not alter the lipid oxidation in OLETF rats (Harada et al. 2004). Therefore, the other pathways may underlie. Concerning with body weight and fat mass, taurine supplementation prevented the high fat diet-induced increase in body weight as well as fat mass in high fat diet-induced obese mice (Tsuboyama-Kasaoka et al. 2006). Then, the effect of taurine on obesity may differ dependent on animal species and/or experimental procedures.

The effect of taurine on fructose-fed rat model

High fructose diet impairs glucose tolerance and insulin sensitivity, taurine supplementation suppressed hyperglycemia and insulin resistance in high fructose-fed rat model (Nandhini et al. 2004, 2005; El Mesallamy et al. 2010). Furthermore, taurine supplementation to high fructose-fed rats decreased in the biomarkers of oxidative stress, such as lipid peroxidation and conjugated dines. Additionally, while taurine improved urinary kallikrein activity in fructose-fed rats, the effect of taurine supplementation was prevented by co-administration of Hoe 140, a kinin B2 receptor antagonist (Nandhini and Anuradha 2002, 2004). Since kinins influence insulin release and insulin action, this action may be involved in the molecular mechanism of the effect of taurine against insulin resistance.

The effect of taurine on insulin secretion and insulin sensitivity in acute glucose or lipid infusion models

Prolonged elevation of glucose is associated with insulin resistance. While 6-h infusion of high glucose induced a decrease in insulin-stimulated peripheral glucose uptake, co-infusion of taurine prevented the defect of glucose uptake (Haber et al. 2003). Furthermore, co-infusion of taurine suppressed lipid peroxidation induced by high glucose infusion in soleus muscle, indicating that antioxidative role of taurine in skeletal muscle is involved in the pathway of effectiveness against peripheral insulin resistance. However, taurine failed to prevent a decrease in glucose-stimulated insulin secretion and an increase in reactive oxygen induced by 48 -h infusion of high glucose (Tang et al. 2007). On the other hand, some reports demonstrated various protective actions of taurine, such as the modulation of mitochondrial calcium handling and the stabilization of protein folding, against high glucose exposure in the cultured beta cells (Han et al. 2004; Kaniuk et al. 2007).

Meanwhile, the beneficial effect of taurine on islet dysfunction induced by free fatty acid was observed (Oprescu et al. 2007). While 48-h intravenous infusion of oleate decreased the glucose-stimulated insulin secretion, co-infusion of taurine prevented defective insulin secretion in islets induced by oleate. Furthermore, taurine suppressed 
oleate-induced ROS production in islets. Moreover, taurine also prevented hepatic insulin resistance induced by intravenous infusion of fatty acids (Wu et al. 2010). This beneficial effect was accompanied by inhibition of fatty acid-induced oxidative stress and JNK1 activation which impairs insulin signaling. These reports indicate the beneficial effect of taurine against lipotoxicity in islets and livers, which in turn may contribute to the prevention of diabetic onset in obesity.

\section{The effect of taurine against diabetic complications and its molecular mechanisms}

\section{Alteration of taurine level in diabetes}

Plasma and tissue taurine level are known to alter in a variety of pathophysiological conditions. Plasma taurine concentration in patients with insulin-dependent diabetes mellitus (IDDM) was significantly lower than in control subjects (Franconi et al. 1995, 1996). Consistently, the reduction of plasma taurine level has been demonstrated in STZ- or alloxan-induced diabetic animals (Franconi et al. 1996; Trachtman et al. 1995). In case of type 2 diabetes, plasma taurine level is lower in the patients than non-diabetic healthy subjects (De Luca et al. 2001; Merheb et al. 2007). Since taurine deficiency associates with dysfunction in various tissues (Hayes et al. 1975; Pion et al. 1987; Sturman 1991), a decrease in taurine level in diabetic subjects may be involved in the diabetic complications.

The role of taurine against the production of advanced glycation end-products and modified LDL

Hyperglycemia accelerates non-enzymatic glycation of protein and causes the accumulation of advanced glycation end products (AGEs). It is known that AGEs play a key role in the development of diabetic complications, such as nephropathy and microvascular diseases. Since taurine has a high reactivity with aldehyde as compared to the other amino acids (Ogasawara et al. 1993), the preventive actions of taurine on the productions of AGEs in diabetes are expected. Indeed, taurine inhibited the AGE formation in vitro (Nandhini et al. 2004; Nandhini and Anuradha 2003; Selvaraj et al. 2006). Consistently, taurine supplementation prevented an increase in the plasma glycated proteins, such as fructosamine and glycated hemoglobin, in high fructosefed rats (Nandhini et al. 2004).

While the modified LDL also contributes to development of vascular complications, some actions of taurine is likely to associate with prevention of LDL modification. The reactivity of taurine with aldehyde is also likely to contribute to decrease in malondialdehyde-related LDL modification (Ogasawara et al. 1993). Moreover, taurine also has the scavenging action for hypochlorous acid ( $\mathrm{HClO})$, while $\mathrm{HClO}$, produced by myeloperoxidase in neutrophils and macrophages, possesses the antimicrobial properties and is also involved in oxidation of LDL (Pennathur and Heinecke 2007). In type 2 diabetic models, high myeloperoxidase activity has been found in the vessels of diabetic obese rats (Zhang et al. 2004), indicating that $\mathrm{HClO}$ may contribute to increase in oxidized LDL in diabetes. Moreover, lowering effect of taurine on the production of LDL-cholesterol itself may contribute the reduction of oxidized LDL (Bellentani et al. 1987; Gandhi et al. 1992; Nakamura-Yamanaka et al. 1987; Yokogoshi et al. 1999). The increased serum level of LDL cholesterol in STZ-treated diabetic mice was normalized by the chronic administration of taurine (Mochizuki et al. 1999; Nanami et al. 1996).

\section{Endothelial dysfunction}

Most of diabetic complications are associated with vascular disorder. Microangiopathy causes retinopathy, nephropathy and neuropathy, whereas macroangiopathy causes cardiomyopathy and atherosclerosis. In STZ-treated diabetic mice, it has been demonstrated that the chronic taurine supplementation normalized the acetylcholine-induced relaxation of aortic rings, while the vasodilatation capacity is attenuated (Kamata et al. 1996; Wang et al. 2008). Furthermore, pre-incubation of the tissues with taurine for 2-h ex vivo improved both the enhanced response to norepinephrine and the attenuated response to acetylcholine in aorta ring from STZ-treated diabetic rats (Abebe 2008). These data illustrate the protective action of taurine on the impaired endothelium-dependent vasodilator response in hyperglycemia.

A variety of molecular mechanisms underlie the beneficial role of taurine against endothelial dysfunction in diabetes mellitus (summarized in Fig. 1). As described above, lowering effect of taurine on AGE and modified LDL may be involved in the molecular pathway of beneficial effect of taurine. Additionally, $\mathrm{HClO}$ consumes the nitric oxide and in turn causes vasoconstriction and endothelial dysfunction (Pennathur and Heinecke 2007). Taurine may increase the bioavailability of NO through scavenging $\mathrm{HClO}$. Furthermore, taurine suppressed the expressions of vascular cell adhesion molecule-1 (VCAM-1) and intercellular adhesion molecule-1 (ICAM-1) induced by high glucose in cultured endothelial cells (Ulrich-Merzenich et al. 2007). Consistently, taurine supplementation started after the diabetes onset in STZ-treated diabetic rats prevented the induction of ICAM-1 and lectin-like oxidized LDL receptor-1 (LOX-1), which is responsible for the incorporation of oxidized LDL into cells, in aortas (Wang 
Fig. 1 Schematic representation of potential pathways involved in the beneficial action of taurine against hyperglycemia-induced endothelial dysfunction. Taurine can inhibit (i) AGE production, (ii) oxidized LDL (oxLDL) production through scavenging malondialdehyde $(M D A)$ and hypochlorous acid $(\mathrm{HClO})$, (iii) $\mathrm{HClO}-d e p e n d e n t$ NO reduction, and (iv) leulocyte-endothelium interaction

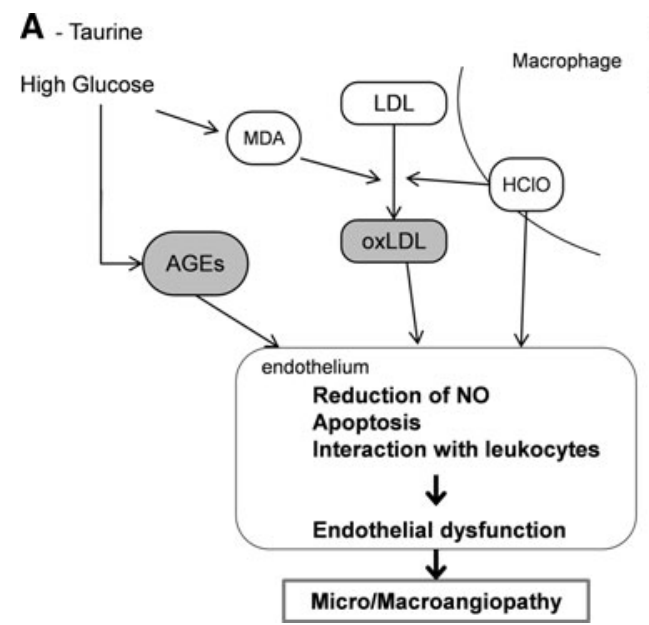

B + Taurine

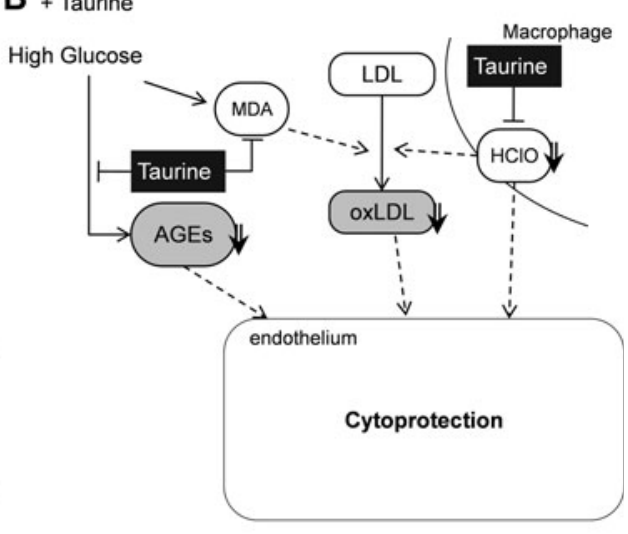

et al. 2008). Furthermore, while acute hyperglycemia induced by intravenous infusion of glucose activated leucocyte adhesion and migration to endothelium and increased in endothelial ICAM-1 and apoptosis in rats, taurine supplementation for 5 days prior to the experiment prevented leucocyte actions and the elevation of ICAM-1 and apoptotic cell death (Casey et al. 2007). Therefore, taurine may prevent the leukocyte-endothelial cell interaction and endothelial apoptosis enhanced by hyperglycemia.

\section{Diabetic nephropathy}

It has been reported that taurine supplementation started concurrently with STZ injection reduced albuminuria and diminished glomerulosclerosis and tubulointerstitial fibrosis (Trachtman et al. 1995). More recently, it has been demonstrated that the taurine administration from fourth month later of the induction of diabetes significantly suppressed further increase in urinary protein excretion in diabetic rats, accompanied by the reduction of mesangial extracellular matrix expansion, TGF- $\beta$ expression and oxidative stress in the renal glomerulus in rats (Higo et al. 2008). In vitro study also demonstrated that taurine treatment suppressed the increases in lipid peroxidation and TGF- $\beta$ by high glucose in renal proximal tubule cells (Park et al. 2001). Moreover, taurine attenuated impairment of cellular growth and tubule cell hypertrophy induced by high glucose, associated with the suppression of high glucose-induced signal activations including MAPK cascade and STAT3 (Huang et al. 2007). Furthermore, taurine attenuated the induction of cytochrome P450 2E1 which metabolizes a variety of endogenous and exogenous compounds and is a potential source of ROS in kidney of STZ-treated diabetic rats (Yao et al. 2009). Taurine also attenuated cell hypertrophy and fibrosis induced by AGE exposure in renal tubular epithelial cells (Huang et al. 2008). Moreover, it has been reported that taurine suppressed the induction of fibrosis-related genes in AGEtreated renal tubular cells (Huang et al. 2009). Therefore, taurine may prevent renal injury and fibrosis in diabetic animals through suppression of ROS induced by glucose and AGE in kidney.

Diabetic retinopathy

In STZ-induced diabetic model, taurine supplementation after diabetic onset effectively improved the changes in ultrastructure and attenuated induction of glial fibrillary acid protein (GFAP), a marker of gliosis, and apoptosis in retinal glial cells of STZ-treated diabetic rats without the effect on plasma glucose concentration (Yu et al. 2008; Zeng et al. 2009, 2010a), indicating the beneficial role of taurine on diabetic retinopathy. Furthermore, the taurine supplementation in STZ-treated rats significantly decreased in retinal carbonyl dienes (Di Leo et al. 2002, 2003). Additionally, taurine supplementation attenuated the induction of retinal VEGF, which associates with vascularization, in STZ-diabetic rats, suggesting that taurine may normalize the retinal vascular function in diabetes (Obrosova et al. 2001b; Zeng et al. 2009). Furthermore, while elevation of glutamate in retina is associated with the development of diabetic retinopathy, taurine prevented the elevation of retinal glutamate content and reduction of the proteins involved in glutamate uptake and degradation in STZ-treated diabetic rats (Zeng et al. 2009). Consistently, taurine suppressed high glucoseinduced defect of glutamate uptake and degradation in cultured Muller cells (Zeng et al. 2010b).

\section{Diabetic cataract}

Taurine is known to be the most abundant free amino acid in eye lens, and lens taurine level is decreased in diabetic cataract group in STZ-treated diabetic rats (Anthrayose and Shashidhar 2004; Malone et al. 1990; Vilchis and Salceda 
1996). Chronic taurine supplementation reduced malondialdehyde level in lens of STZ-induced diabetic rats (Obrosova and Stevens 1999). Furthermore, although taurine did not improve opacity of eye lens induced by the exposure to high glucose medium for 6 days in cultured lens, taurine inhibited protein carbonylation induced by high glucose (Son et al. 2007). These studies indicate that taurine protects the lens from oxidative stress induced by hyperglycemia, while the effect of taurine against cataract is arguable.

\section{Diabetic neuropathy}

It is well-known that sorbitol accumulation in the nerve is associated with diabetic peripheral neuropathy. When intracellular glucose is increased in hyperglycemic condition, excessive glucose is metabolized to sorbitol through aldose reductase. Organic osmolytes, including sorbitol, taurine and myo-inositol, are regulated in response to the change of extracellular osmolality to maintain the cell volume. Stevens demonstrated that taurine and myo-inositol are decreased in nerve of STZ-treated diabetic rats, whereas administration of aldose reductase inhibitor attenuated the depletion of taurine and myo-inositol (Stevens et al. 1993), suggesting that excessive accumulation of sorbitol led to the depletion of other organic osmolytes. Interestingly, the exposure of cells to high glucose reduces the expression of taurine transporter, whereas the treatment of an aldose reductase inhibitor or an antioxidant with the high glucose reversed the expression of taurine transporter (Askwith et al. 2009; Stevens et al. 1999), suggesting the crucial role of sorbitol in the regulation of intracellular taurine concentration. While diabetic neuropathy is observed in STZtreated diabetic model, taurine supplementation improved the defective nerve functions, such as nerve conductance deficits and hyperalgesia, and ameliorated the deficit of nerve blood flow (Li et al. 2005b; Obrosova et al. 2001a, b; Pop-Busui et al. 2001; Stevens et al. 1993). Taurine supplementation reduced the oxidative stress in nerves and prevented the impairment of calcium handling in sensory neuron of STZ-treated diabetic rats (Li et al. 2005b). Additionally, a decrease in nerve growth factor (NGF) in STZ-treated rats was prevented by taurine supplementation (Obrosova et al. 2001a). Similarly, usefulness of taurine against diabetic peripheral neuropathy, including deficits of hind limb sciatic motor and digital sensory nerve conduction velocity, nerve blood flow, and sensory thresholds, was observed in Zucker diabetic fatty rats (Li et al. 2006).

Atherosclerosis and thrombosis

Diabetes is a major risk factor of atherosclerosis. While there are several reports on the beneficial effects of taurine against atherosclerosis (Kondo et al. 2000; Murakami et al. 1999a, 1999b, 2002), no evidence has been demonstrated in the diabetic models. Since endothelial dysfunction and accumulation of oxidized LDL in vessel are the critical features of atherosclerosis, various actions of taurine in endothelial cells mentioned above, such as lowering oxidized LDL and anti-apoptosis, can work effectively on atherosclerosis in diabetes.

Moreover, platelet activation and aggregation caused by atherosclerosis are the critical events in thrombosis. It is known that platelet function alters in diabetic subjects, which may sensitize the platelet for stresses to generate thrombi. It has been reported that platelet taurine level as well as plasma taurine level is decreased in both type 1 and type 2 diabetic patients (De Luca et al. 2001; Franconi et al. 1995). Because taurine depletion causes an increase in platelet sensitivity to aggregation (Hayes et al. 1989), it has been hypothesized that taurine supplementation can prevent platelet aggregation in diabetic patients. Franconi et al. (1995) reported that taurine supplementation at $1.5 \mathrm{~g} /$ day for 90 days in IDDM patients suppressed platelet aggregation induced by arachidonic acid in the isolated platelet. Additionally, they demonstrated the preincubation of taurine inhibits arachidonic acid-induced aggregation in platelet from diabetic patients, but not in platelet from control subjects. Spohr et al. (2005) demonstrated that taurine supplementation at $1.5 \mathrm{~g} /$ day for 8 weeks had no effect on ADP-stimulated platelet aggregation in high risk subjects with a positive family history of NIDDM.

\section{Diabetic cardiomyopathy}

Unlike the other tissues, cardiac taurine level increases in STZ-treated diabetic models and does not alter in obeseinduced diabetic models (Militante et al. 2000). Elevation of cardiac taurine level seems the feature of cardiomyopathy, since its elevation has also been reported in the animal models or patients with congestive heart failure (Huxtable and Bressler 1974). Although the biological significance of the elevation of taurine level in the failing heart is still unveiled, the elevated taurine is expected to modulate glycolytic capacity, such as pyruvate dehydrogenase phosphorylation, in diabetic cardiomyopathy (Militante et al. 2000). Recently, Li et al. (2005a) reported that taurine supplementation started after the development of cardiomyopathy prevented an increase in heart weight and improved the impaired $-\mathrm{dp} / \mathrm{dt} \max$ but not $+\mathrm{dp} / \mathrm{dt}$ max. Furthermore, taurine supplementation suppressed the reduction of Bcl-2 expression in STZ-treated diabetic cardiomyopathy rats, indicating that anti-apoptotic action of taurine may be involved in the protective effect of taurine against diabetic cardiomyopathy. 


\section{Clinical studies}

The clinical usefulness of taurine on diabetes has been evaluated in some clinical studies (listed in Table 1). In clinical trial for type 1 diabetic patients, Elizarova and Nedosugova (1996) investigated the effect of taurine on hyperglycemia in type 1 diabetic patients $(n=10)$ who had been already medicated with insulin. Additive supplementation of taurine ( $0.5 \mathrm{~g}$ twice a day) improved the carbohydrate metabolism and decreased in triglyceride. In the other study, however, Franconi et al. (1995) reported that the administration of taurine ( $1.5 \mathrm{~g}$ per day) for 90 day did not modify glucose metabolism in IDDM patients $(n=39)$. Clinical usefulness on type 1 diabetes is still arguable.

There are some clinical trials of taurine supplementation on the patients with type 2 diabetes mellitus. Chauncey et al. (2003) tested the hypoglycemic effect of taurine on type2 diabetes patients $(n=32)$, and they showed that taurine supplementation ( $3 \mathrm{~g}$ per day) for 4 month increased in plasma taurine level but did not change HbAlc level and the plasma lipid peroxide level compared to placebo group. Brons et al. (2004) also tested the effect of taurine in overweight non-diabetic men $(n=20)$ in crossover study. Although plasma taurine level was elevated after taurine administration ( $1.5 \mathrm{~g}$ per day) for 8 weeks, taurine had no effects on insulin secretion or sensitivity, and on plasma lipid level. These studies concluded that taurine does not influence hyperglycemia and insulin resistance in type 2 diabetic patients, inconsistent with animal studies. However, it should be noted that these clinical studies have some limitations such as other medications, given dose of taurine, duration of trial etc. On the other hand, usefulness of taurine supplementation against the impairment of insulin sensitivity was reported in the crossover clinical study by Xiao et al. (2008). They demonstrated the effect of taurine against chronic elevation of plasma fatty acids induced by the intravenous infusion of Intralipid (20\% soybean oil, $1.2 \%$ egg phospholipids, $2.25 \%$ glycerin in water, heparin) on non-diabetic men who were either overweight or obese $(n=6)$. While 48 -h infusion of intravenous lipid induced insulin resistance, a 2-week pretreatment of taurine ( $3 \mathrm{~g}$ per day) before lipid infusion improved the impaired insulin sensitivity and prevented the rise in lipid peroxidation products in plasma, indicating that oral taurine supplementation ameliorates fatty acid-induced insulin resistance in humans, possibly due to reducing oxidative stress.

Concerning diabetic nephropathy, Nakamura et al. (1999) tested the taurine supplementation ( $3 \mathrm{~g}$ per day) on the patients with microalbuminemia of type 2 diabetes and treatment was continued for 12 months in intergroup trial ( $n=10$ each group). They demonstrated that taurine supplementation had no benefit against microalbuminemia and the biomarkers for fibrosis, such as serum collagen IV and plasma Matrix metalloproteinase-9.

Meanwhile, Moloney et al. (2010) recently reported the beneficial effect of taurine on endothelial dysfunction in type 1 diabetic patients in crossover study. While arterial stiffness and flow-mediated dilatation of brachial artery,

Table 1 Clinical studies with diabetes and complications

\begin{tabular}{|c|c|c|c|c|c|}
\hline Article & Subjects & Duration & Dose (/day) & Endpoint & Result \\
\hline \multicolumn{6}{|l|}{ Diabetes } \\
\hline Franconi et al. (1995) & IDDM patients $(n=39)$ & 90 days & $1.5 \mathrm{~g}$ & Glucose metabolism & $\mathrm{NC}$ \\
\hline $\begin{array}{l}\text { Elizarova and Nedosugova } \\
\text { (1996) }\end{array}$ & IDDM patients $(n=10)$ & 30 days & $1 \mathrm{~g}$ & $\begin{array}{l}\text { Glucose metabolism } \\
\text { Triglyceride }\end{array}$ & $\begin{array}{l}\text { Improved } \\
\text { Decreased }\end{array}$ \\
\hline Chauncey et al. (2003) & NIDDM patients $(n=32)$ & 4 months & $3 \mathrm{~g}$ & $\begin{array}{l}\text { HbA1c } \\
\text { Plasma lipid peroxide level }\end{array}$ & $\begin{array}{l}\mathrm{NC} \\
\mathrm{NC}\end{array}$ \\
\hline Brons et al. (2004) & $\begin{array}{l}\text { Overweight non-diabetic } \\
\text { men }(n=20)\end{array}$ & 8 weeks & $1.5 \mathrm{~g}$ & $\begin{array}{l}\text { Insulin secretion } \\
\text { Plasma lipid level }\end{array}$ & $\begin{array}{l}\mathrm{NC} \\
\mathrm{NC}\end{array}$ \\
\hline Xiao et al. (2008) & $\begin{array}{l}\text { Overweight non-diabetic } \\
\text { men }(n=6)\end{array}$ & 2 weeks & $3 \mathrm{~g}$ & $\begin{array}{l}\text { Insulin sensitivity impaired by } 48-\mathrm{h} \\
\text { infusion of intravenous lipid } \\
\text { Lipid peroxidation products }\end{array}$ & $\begin{array}{l}\text { Improved } \\
\text { Decreased }\end{array}$ \\
\hline \multicolumn{6}{|l|}{ Complications } \\
\hline Nakamura et al. (1999) & $\begin{array}{l}\text { NIDDM patients with } \\
\text { microalbuminemia } \\
(n=10 \text { each group })\end{array}$ & 12 months & $3 \mathrm{~g}$ & $\begin{array}{l}\text { Microalbuminemia } \\
\text { Biomarkers for fibrosis }\end{array}$ & $\begin{array}{l}\mathrm{NC} \\
\mathrm{NC}\end{array}$ \\
\hline Moloney et al. (2010) & IDDM patients $(n=9)$ & 2 weeks & $1.5 \mathrm{~g}$ & $\begin{array}{l}\text { Hyperglycemia } \\
\text { Endothelium-dependent reaction }\end{array}$ & $\begin{array}{l}\mathrm{NC} \\
\text { Improved }\end{array}$ \\
\hline
\end{tabular}

$N C$ Not changed 
which are endothelium-dependent reactions, were low in diabetic patients as compared to control subjects, taurine supplementation ( $1.5 \mathrm{~g}$ per day) for 2 weeks returned these parameters to control level without hypoglycemic effect, indicating the protective role of taurine on endothelium. Interestingly, same group previously reported that taurine supplementation ( $1.5 \mathrm{~g}$ per day) for 2 weeks also attenuated the impairment of flow-mediated dilatation in young cigarette smokers (Fennessy et al. 2003). Furthermore, while the culture medium conditioned with monocytes taken from smokers impaired the release of nitric oxide and increased in endothelin-1 in HUVECs, the levels of nitric oxide and endothelin-1 returned to control levels in HUVECs cultured with the monocyte-conditioned medium taken from smokers who had been treated with taurine. Therefore, the suppression of monocyte-endothelium interaction is likely to be a key action of protective role of taurine on endothelial function. Since the involvement of monocyte-endothelium interaction in endothelial dysfunction of diabetic animal models is also demonstrated as described above, it is possible that same pathway underlies the action of taurine against endothelial dysfunction in diabetic patients.

\section{Discussion}

As described in this article, numerous studies revealed that taurine supplementation is beneficial to diabetes and its complications in several animal models. Moreover, multiple actions of taurine coordinate to protect from diabetes and complications (Table 2). Especially, suppressive effect of taurine against oxidative stress is associated with various pathways in diabetic condition. First, reactivity of taurine against aldehyde can contribute to the reduction of AGE and modified LDL. Second, scavenging action against $\mathrm{HClO}$ can reduce the LDL modification and increase in bioavailability of the NO. Finally, taurine is likely to inhibit the ROS production via regulation of mitochondria (reviewed in Schaffer et al. 2009). While very high taurine concentration is found in mitochondria, several roles of taurine in mitochondria have been proposed. Taurinecontaining modified uridine has recently been discovered at wobble position in mitochondrial transfer RNA (tRNA) (Suzuki et al. 2002). Taurine-modified tRNA may play a crucial role in the translation of proteins responsible for electron transport (Kirino et al. 2004), suggesting that taurine depletion might cause a decrease in taurine-modified tRNA and impairs electron transport capacity. Moreover, buffering property of taurine in mitochondrial matrix has been reported (Hansen et al. 2010). Therefore, taurine depletion in diabetes may contribute to mitochondrial dysfunction and it is possible that restoration of taurine contributes to normalize mitochondrial function, which may associate with inhibition of the ROS production from mitochondria. To elucidate the role of taurine depletion in mitochondrial function and in the development of diabetic complications, further studies, such as investigations using taurine transporter knock-out animals (Ito et al. 2008), will be required.

Nevertheless, most of clinical studies failed to prove the beneficial role of taurine on insulin resistance and diabetic
Table 2 Molecular mechanisms involved in the beneficial effect of taurine against diabetic complications

\begin{tabular}{ll}
\hline Diabetic complications & Effects of taurine \\
\hline Endothelial dysfunction & - Prevention of AGE production \\
& - Scavenging aldehydes $\rightarrow$ oxidized LDL $\downarrow$ \\
& - Scavenging HClO $\rightarrow$ oxidized LDL $\downarrow$, NO $\uparrow$ \\
& - LDL cholesterol $\downarrow$ \\
& - Inhibition of apoptosis in endothelial cells \\
& - Prevention of VCAM-1, ICAM-1 $\uparrow \rightarrow$ leukocyte-endothelium interaction $\downarrow$ \\
& - TGF- $\beta \downarrow \rightarrow$ prevention of fibrosis \\
Diabetic nephropathy & - Suppression of MAPK cascade, STAT3 $\rightarrow$ cell growth \\
& - Cytochrome P450 2E1 $\downarrow \rightarrow$ oxidative stress $\downarrow$ \\
Diabetic retinopathy & - Oxidative stress $\downarrow \rightarrow$ prevention of Na+/K+/ATPase activity $\downarrow$ \\
Diabetic cataract & - Suppression of VEGF $\uparrow \rightarrow$ retinal vascular function \\
Diabetic neuropathy & - Oxidative stress $\downarrow$ \\
& - Oxidative stress $\downarrow$ in nerves \\
Diabetic cardiomyopathy & - Srevention of the impaired calcium handling in sensory neuron \\
\hline
\end{tabular}


complications, whereas the others revealed the effectiveness. The discrepancies between animal experiments and clinical trials might be due to some limitations of clinical studies, such as a severity of the disease, other medications, given dose, duration of trial etc. Especially, the given dose of taurine per body weight is more than 10 times higher in animal experiments (e.g. diet containing 5\% taurine) than in clinical trials (1.5-3 g taurine per day). Intake of taurine is thought to be quite safe as well as the amino acids found in food. While several reports strongly support that taurine is safe at levels up to $3 \mathrm{~g} /$ day, several clinical trials tested higher taurine dosages without adverse effects (Azuma et al. 1983, 1985; Shao and Hathcock 2008). Furthermore, since the pharmacological effect of taurine seems mild but not powerful, simultaneous therapy by using some medicines is also a problem. At present none of clinical studies have a sufficient numbers of patients. Therefore, long-term surveillance with large numbers of patients may be necessary to elucidate the effectiveness of taurine against diabetes or its complications in clinical study. Moreover, life style, such as diet, and genetic factors, such as genomic polymorphisms which relate to individual differences, can affect to the result of trials. It is known that urinary taurine concentration in human varies widely among individuals (Yamori et al. 2001). Brons et al. (2004) reported a wide variation in the increasing rate of plasma taurine concentration after taurine administration among individuals. These variations of taurine movement among individuals must differ dependent not only on life style but also genomic polymorphisms in taurine-related genes associated with the kinetics of taurine, such as taurine transporter. Therefore, we believe that the discovery of the genetic factors which determine the variation of taurine movement will help to elucidate the effectiveness of taurine against diabetes and its complications in humans.

Acknowledgments This work is supported by Grant-in-aid from Ministry of Education, Science, Sports and Culture of Japan. This work is also supported by a research grant from Taisho Pharmaceutical Co. Ltd.

Open Access This article is distributed under the terms of the Creative Commons Attribution Noncommercial License which permits any noncommercial use, distribution, and reproduction in any medium, provided the original author(s) and source are credited.

\section{References}

Abebe W (2008) Effects of taurine on the reactivity of aortas from diabetic rats. Life Sci 82:279-289

Alvarado-Vasquez N, Zamudio P, Ceron E, Vanda B, Zenteno E, Carvajal-Sandoval G (2003) Effect of glycine in streptozotocininduced diabetic rats. Comp Biochem Physiol C Toxicol Pharmacol 134:521-527
Anthrayose CV, Shashidhar S (2004) Studies on protein and taurine in normal, senile and diabetic cataractous human lenses. Indian $\mathbf{J}$ Physiol Pharmacol 48:357-360

Arany E, Strutt B, Romanus P, Remacle C, Reusens B, Hill DJ (2004) Taurine supplement in early life altered islet morphology, decreased insulitis and delayed the onset of diabetes in nonobese diabetic mice. Diabetologia 47:1831-1837

Askwith T, Zeng W, Eggo MC, Stevens MJ (2009) Oxidative stress and dysregulation of the taurine transporter in high-glucoseexposed human Schwann cells: implications for pathogenesis of diabetic neuropathy. Am J Physiol Endocrinol Metab 297:E620E628

Azuma J, Hasegawa H, Sawamura A, Awata N, Ogura K, Harada H, Yamamura Y, Kishimoto S (1983) Therapy of congestive heart failure with orally administered taurine. Clin Ther 5:398-408

Azuma J, Sawamura A, Awata N, Ohta H, Hamaguchi T, Harada H, Takihara K, Hasegawa H, Yamagami T, Ishiyama T et al (1985) Therapeutic effect of taurine in congestive heart failure: a double-blind crossover trial. Clin Cardiol 8:276-282

Bellentani S, Pecorari M, Cordoma P, Marchegiano P, Manenti F, Bosisio E, De Fabiani E, Galli G (1987) Taurine increases bile acid pool size and reduces bile saturation index in the hamster. J Lipid Res 28:1021-1027

Brons C, Spohr C, Storgaard H, Dyerberg J, Vaag A (2004) Effect of taurine treatment on insulin secretion and action, and on serum lipid levels in overweight men with a genetic predisposition for type II diabetes mellitus. Eur J Clin Nutr 58:1239-1247

Casey RG, Gang C, Joyce M, Bouchier-Hayes DJ (2007) Taurine attenuates acute hyperglycaemia-induced endothelial cell apoptosis, leucocyte-endothelial cell interactions and cardiac dysfunction. J Vasc Res 44:31-39

Chang KJ, Kwon W (2000) Immunohistochemical localization of insulin in pancreatic beta-cells of taurine-supplemented or taurine-depleted diabetic rats. Adv Exp Med Biol 483:579-587

Chauncey KB, Tenner TE Jr, Lombardini JB, Jones BG, Brooks ML, Warner RD, Davis RL, Ragain RM (2003) The effect of taurine supplementation on patients with type 2 diabetes mellitus. Adv Exp Med Biol 526:91-96

De Luca G, Calpona PR, Caponetti A, Romano G, Di Benedetto A, Cucinotta D, Di Giorgio RM (2001) Taurine and osmoregulation: platelet taurine content, uptake, and release in type 2 diabetic patients. Metabolism 50:60-64

Di Leo MA, Santini SA, Cercone S, Lepore D, Gentiloni Silveri N, Caputo S, Greco AV, Giardina B, Franconi F, Ghirlanda G (2002) Chronic taurine supplementation ameliorates oxidative stress and $\mathrm{Na}^{+} \mathrm{K}^{+}$ATPase impairment in the retina of diabetic rats. Amino Acids 23:401-406

Di Leo MA, Ghirlanda G, Gentiloni Silveri N, Giardina B, Franconi F, Santini SA (2003) Potential therapeutic effect of antioxidants in experimental diabetic retina: a comparison between chronic taurine and vitamin E plus selenium supplementations. Free Radic Res 37:323-330

Di Leo MA, Santini SA, Gentiloni Silveri N, Giardina B, Franconi F, Ghirlanda G (2004) Long-term taurine supplementation reduces mortality rate in streptozotocin-induced diabetic rats. Amino Acids 27:187-191

El Mesallamy HO, El-Demerdash E, Hammad LN, El Magdoub HM (2010) Effect of taurine supplementation on hyperhomocysteinemia and markers of oxidative stress in high fructose diet induced insulin resistance. Diabetol Metab Syndr 2(46):46

Elizarova EP, Nedosugova LV (1996) First experiments in taurine administration for diabetes mellitus. The effect on erythrocyte membranes. Adv Exp Med Biol 403:583-588

Fennessy FM, Moneley DS, Wang JH, Kelly CJ, Bouchier-Hayes DJ (2003) Taurine and vitamin C modify monocyte and endothelial dysfunction in young smokers. Circulation 107:410-415 
Franconi F, Bennardini F, Mattana A, Miceli M, Ciuti M, Mian M, Gironi A, Anichini R, Seghieri G (1995) Plasma and platelet taurine are reduced in subjects with insulin-dependent diabetes mellitus: effects of taurine supplementation. Am J Clin Nutr 61:1115-1119

Franconi F, Miceli M, Fazzini A, Seghieri G, Caputo S, DiLeo MA, Lepore D, Ghirlanda G (1996) Taurine and diabetes. Humans and experimental models. Adv Exp Med Biol 403:579-582

Franconi F, Di Leo MA, Bennardini F, Ghirlanda G (2004) Is taurine beneficial in reducing risk factors for diabetes mellitus? Neurochem Res 29:143-150

Franconi F, Loizzo A, Ghirlanda G, Seghieri G (2006) Taurine supplementation and diabetes mellitus. Curr Opin Clin Nutr Metab Care 9:32-36

Gandhi VM, Cherian KM, Mulky MJ (1992) Hypolipidemic action of taurine in rats. Indian J Exp Biol 30:413-417

Gavrovskaya LK, Ryzhova OV, Safonova AF, Matveev AK, Sapronov NS (2008) Protective effect of taurine on rats with experimental insulin-dependent diabetes mellitus. Bull Exp Biol Med 146:226-228

Goodman HO, Shihabi ZK (1990) Supplemental taurine in diabetic rats: effects on plasma glucose and triglycerides. Biochem Med Metab Biol 43:1-9

Haber CA, Lam TK, Yu Z, Gupta N, Goh T, Bogdanovic E, Giacca A, Fantus IG (2003) N-acetylcysteine (NAC) and taurine prevent hyperglycemia-induced insulin resistance in vivo: possible role of oxidative stress. Am J Physiol Endocrinol Metab 285:E744E753

Han J, Bae JH, Kim SY, Lee HY, Jang BC, Lee IK, Cho CH, Lim JG, Suh SI, Kwon TK et al (2004) Taurine increases glucose sensitivity of UCP2-overexpressing beta-cells by ameliorating mitochondrial metabolism. Am J Physiol Endocrinol Metab 287:E1008-E1018

Hansen SH (2001) The role of taurine in diabetes and the development of diabetic complications. Diabetes Metab Res Rev 17:330-346

Hansen SH, Andersen ML, Cornett C, Gradinaru R, Grunnet N (2010) A role for taurine in mitochondrial function. J Biomed Sci 17(Suppl 1):S23

Harada N, Ninomiya C, Osako Y, Morishima M, Mawatari K, Takahashi A, Nakaya Y (2004) Taurine alters respiratory gas exchange and nutrient metabolism in type 2 diabetic rats. Obes Res 12:1077-1084

Hayes KC, Carey RE, Schmidt SY (1975) Retinal degeneration associated with taurine deficiency in the cat. Science 188:949-951

Hayes KC, Pronczuk A, Addesa AE, Stephan ZF (1989) Taurine modulates platelet aggregation in cats and humans. Am J Clin Nutr 49:1211-1216

Higo S, Miyata S, Jiang QY, Kitazawa R, Kitazawa S, Kasuga M (2008) Taurine administration after appearance of proteinuria retards progression of diabetic nephropathy in rats. Kobe J Med Sci 54:E35-E45

Huang JS, Chuang LY, Guh JY, Huang YJ, Hsu MS (2007) Antioxidants attenuate high glucose-induced hypertrophic growth in renal tubular epithelial cells. Am J Physiol Renal Physiol 293:F1072-F1082

Huang JS, Chuang LY, Guh JY, Yang YL, Hsu MS (2008) Effect of taurine on advanced glycation end products-induced hypertrophy in renal tubular epithelial cells. Toxicol Appl Pharmacol 233:220-226

Huang JS, Chuang LY, Guh JY, Huang YJ (2009) Effects of nitric oxide and antioxidants on advanced glycation end productsinduced hypertrophic growth in human renal tubular cells. Toxicol Sci 111(1):109-119

Huxtable RJ (1992) Physiological actions of taurine. Physiol Rev $72: 101-163$
Huxtable R, Bressler R (1974) Taurine concentrations in congestive heart failure. Science 184:1187-1188

Ito T, Kimura Y, Uozumi Y, Takai M, Muraoka S, Matsuda T, Ueki K, Yoshiyama M, Ikawa M, Okabe M, Schaffer SW, Fujio Y, Azuma J (2008) Taurine depletion caused by knocking out the taurine transporter gene leads to cardiomyopathy with cardiac atrophy. J Mol Cell Cardiol 44:927-937

Kamata K, Sugiura M, Kojima S, Kasuya Y (1996) Restoration of endothelium-dependent relaxation in both hypercholesterolemia and diabetes by chronic taurine. Eur J Pharmacol 303:47-53

Kaniuk NA, Kiraly M, Bates H, Vranic M, Volchuk A, Brumell JH (2007) Ubiquitinated-protein aggregates form in pancreatic betacells during diabetes-induced oxidative stress and are regulated by autophagy. Diabetes 56:930-939

Kirino Y, Yasukawa T, Ohta S, Akira S, Ishihara K, Watanabe K, Suzuki T (2004) Codon-specific translational defect caused by a wobble modification deficiency in mutant tRNA from a human mitochondrial disease. Proc Natl Acad Sci USA 101:15070_ 15075

Kondo Y, Murakami S, Oda H, Nagate T (2000) Taurine reduces atherosclerotic lesion development in apolipoprotein E-deficient mice. Adv Exp Med Biol 483:193-202

Li C, Cao L, Zeng Q, Liu X, Zhang Y, Dai T, Hu D, Huang K, Wang Y, Wang X et al (2005a) Taurine may prevent diabetic rats from developing cardiomyopathy also by downregulating angiotensin II type2 receptor expression. Cardiovasc Drugs Ther 19:105-112

Li F, Obrosova IG, Abatan O, Tian D, Larkin D, Stuenkel EL, Stevens MJ (2005b) Taurine replacement attenuates hyperalgesia and abnormal calcium signaling in sensory neurons of STZ-D rats. Am J Physiol Endocrinol Metab 288:E29-E36

Li F, Abatan OI, Kim H, Burnett D, Larkin D, Obrosova IG, Stevens MJ (2006) Taurine reverses neurological and neurovascular deficits in Zucker diabetic fatty rats. Neurobiol Dis 22:669-676

Malone JI, Lowitt S, Cook WR (1990) Nonosmotic diabetic cataracts. Pediatr Res 27:293-296

Merheb M, Daher RT, Nasrallah M, Sabra R, Ziyadeh FN, Barada K (2007) Taurine intestinal absorption and renal excretion test in diabetic patients: a pilot study. Diabetes Care 30:2652-2654

Militante JD, Lombardini JB, Schaffer SW (2000) The role of taurine in the pathogenesis of the cardiomyopathy of insulin-dependent diabetes mellitus. Cardiovasc Res 46:393-402

Mochizuki H, Takido J, Oda H, Yokogoshi H (1999) Improving effect of dietary taurine on marked hypercholesterolemia induced by a high-cholesterol diet in streptozotocin-induced diabetic rats. Biosci Biotechnol Biochem 63:1984-1987

Moloney MA, Casey RG, O'Donnell DH, Fitzgerald P, Thompson C, Bouchier-Hayes DJ (2010) Two weeks taurine supplementation reverses endothelial dysfunction in young male type 1 diabetics. Diab Vasc Dis Res 7:300-310

Murakami S, Kondo Y, Tomisawa K, Nagate T (1999a) Prevention of atherosclerotic lesion development in mice by taurine. Drugs Exp Clin Res 25:227-234

Murakami S, Kondo-Ohta Y, Tomisawa K (1999b) Improvement in cholesterol metabolism in mice given chronic treatment of taurine and fed a high-fat diet. Life Sci 64:83-91

Murakami S, Kondo Y, Sakurai T, Kitajima H, Nagate T (2002) Taurine suppresses development of atherosclerosis in Watanabe heritable hyperlipidemic (WHHL) rabbits. Atherosclerosis 163:79-87

Nakamura T, Ushiyama C, Suzuki S, Shimada N, Ohmuro H, Ebihara I, Koide H (1999) Effects of taurine and vitamin $\mathrm{E}$ on microalbuminuria, plasma metalloproteinase-9, and serum type IV collagen concentrations in patients with diabetic nephropathy. Nephron 83:361-362

Nakamura-Yamanaka Y, Tsuji K, Ichikawa T (1987) Effect of dietary taurine on cholesterol 7 alpha-hydroxylase activity in the liver of 
mice fed a lithogenic diet. J Nutr Sci Vitaminol (Tokyo) 33:239-243

Nakaya Y, Minami A, Harada N, Sakamoto S, Niwa Y, Ohnaka M (2000) Taurine improves insulin sensitivity in the Otsuka LongEvans Tokushima Fatty rat, a model of spontaneous type 2 diabetes. Am J Clin Nutr 71:54-58

Nanami K, Oda H, Yokogoshi H (1996) Antihypercholesterolemic action of taurine on streptozotocin-diabetic rats or on rats fed a high cholesterol diet. Adv Exp Med Biol 403:561-568

Nandhini AT, Anuradha CV (2002) Taurine modulates kallikrein activity and glucose metabolism in insulin resistant rats. Amino Acids 22:27-38

Nandhini TA, Anuradha CV (2003) Inhibition of lipid peroxidation, protein glycation and elevation of membrane ion pump activity by taurine in RBC exposed to high glucose. Clin Chim Acta 336:129-135

Nandhini AT, Anuradha CV (2004) Hoe 140 abolishes the blood pressure lowering effect of taurine in high fructose-fed rats. Amino Acids 26:299-303

Nandhini AT, Thirunavukkarasu V, Anuradha CV (2004) Stimulation of glucose utilization and inhibition of protein glycation and AGE products by taurine. Acta Physiol Scand 181:297-303

Nandhini AT, Thirunavukkarasu V, Ravichandran MK, Anuradha CV (2005) Effect of taurine on biomarkers of oxidative stress in tissues of fructose-fed insulin-resistant rats. Singapore Med J 46:82-87

Obrosova IG, Stevens MJ (1999) Effect of dietary taurine supplementation on GSH and NAD(P)-redox status, lipid peroxidation, and energy metabolism in diabetic precataractous lens. Invest Ophthalmol Vis Sci 40:680-688

Obrosova IG, Fathallah L, Stevens MJ (2001a) Taurine counteracts oxidative stress and nerve growth factor deficit in early experimental diabetic neuropathy. Exp Neurol 172:211-219

Obrosova IG, Minchenko AG, Marinescu V, Fathallah L, Kennedy A, Stockert CM, Frank RN, Stevens MJ (2001b) Antioxidants attenuate early up regulation of retinal vascular endothelial growth factor in streptozotocin-diabetic rats. Diabetologia 44:1102-1110

Ogasawara M, Nakamura T, Koyama I, Nemoto M, Yoshida T (1993) Reactivity of taurine with aldehydes and its physiological role. Chem Pharm Bull (Tokyo) 41:2172-2175

Oprescu AI, Bikopoulos G, Naassan A, Allister EM, Tang C, Park E, Uchino H, Lewis GF, Fantus IG, Rozakis-Adcock M et al (2007) Free fatty acid-induced reduction in glucose-stimulated insulin secretion: evidence for a role of oxidative stress in vitro and in vivo. Diabetes 56:2927-2937

Park SH, Choi HJ, Lee JH, Woo CH, Kim JH, Han HJ (2001) High glucose inhibits renal proximal tubule cell proliferation and involves PKC, oxidative stress, and TGF-beta 1. Kidney Int 59:1695-1705

Pennathur S, Heinecke JW (2007) Oxidative stress and endothelial dysfunction in vascular disease. Curr Diab Rep 7:257-264

Pion PD, Kittleson MD, Rogers QR, Morris JG (1987) Myocardial failure in cats associated with low plasma taurine: a reversible cardiomyopathy. Science 237:764-768

Pop-Busui R, Sullivan KA, Van Huysen C, Bayer L, Cao X, Towns R, Stevens MJ (2001) Depletion of taurine in experimental diabetic neuropathy: implications for nerve metabolic, vascular, and functional deficits. Exp Neurol 168:259-272

Satoh H (1998) Cardiac actions of taurine as a modulator of the ion channels. Adv Exp Med Biol 442:121-128

Schaffer S, Takahashi K, Azuma J (2000) Role of osmoregulation in the actions of taurine. Amino Acids 19:527-546

Schaffer SW, Azuma J, Mozaffari M (2009) Role of antioxidant activity of taurine in diabetes. Can $\mathrm{J}$ Physiol Pharmacol 87:91-99
Selvaraj N, Bobby Z, Sathiyapriya V (2006) Effect of lipid peroxides and antioxidants on glycation of hemoglobin: an in vitro study on human erythrocytes. Clin Chim Acta 366:190-195

Shao A, Hathcock JN (2008) Risk assessment for the amino acids taurine, L-glutamine and L-arginine. Regul Toxicol Pharmacol 50:376-399

Sjovall J (1959) Dietary glycine and taurine on bile acid conjugation in man; bile acids and steroids 75. Proc Soc Exp Biol Med 100:676-678

Son HY, Kim H, Y HK (2007) Taurine prevents oxidative damage of high glucose-induced cataractogenesis in isolated rat lenses. J Nutr Sci Vitaminol (Tokyo) 53:324-330

Spohr C, Brons C, Winther K, Dyerberg J, Vaag A (2005) No effect of taurine on platelet aggregation in men with a predisposition to type 2 diabetes mellitus. Platelets 16:301-305

Stevens MJ, Lattimer SA, Kamijo M, Van Huysen C, Sima AA, Greene DA (1993) Osmotically-induced nerve taurine depletion and the compatible osmolyte hypothesis in experimental diabetic neuropathy in the rat. Diabetologia 36:608-614

Stevens MJ, Hosaka Y, Masterson JA, Jones SM, Thomas TP, Larkin DD (1999) Downregulation of the human taurine transporter by glucose in cultured retinal pigment epithelial cells. Am J Physiol 277:E760-E771

Sturman JA (1991) Dietary taurine and feline reproduction and development. J Nutr 121:S166-S170

Suzuki T, Suzuki T, Wada T, Saigo K, Watanabe K (2002) Taurine as a constituent of mitochondrial tRNAs: new insights into the functions of taurine and human mitochondrial diseases. EMBO J 21:6581-6589

Tang C, Han P, Oprescu AI, Lee SC, Gyulkhandanyan AV, Chan GN, Wheeler MB, Giacca A (2007) Evidence for a role of superoxide generation in glucose-induced beta-cell dysfunction in vivo. Diabetes 56:2722-2731

Tenner TE Jr, Zhang XJ, Lombardini JB (2003) Hypoglycemic effects of taurine in the alloxan-treated rabbit, a model for type 1 diabetes. Adv Exp Med Biol 526:97-104

Tokunaga H, Yoneda Y, Kuriyama K (1979) Protective actions of taurine against streptozotocin-induced hyperglycemia. Biochem Pharmacol 28:2807-2811

Tokunaga H, Yoneda Y, Kuriyama K (1983) Streptozotocin-induced elevation of pancreatic taurine content and suppressive effect of taurine on insulin secretion. Eur J Pharmacol 87:237-243

Trachtman H, Futterweit S, Maesaka J, Ma C, Valderrama E, Fuchs A, Tarectecan AA, Rao PS, Sturman JA, Boles TH et al (1995) Taurine ameliorates chronic streptozocin-induced diabetic nephropathy in rats. Am J Physiol 269:F429-F438

Tsuboyama-Kasaoka N, Shozawa C, Sano K, Kamei Y, Kasaoka S, Hosokawa Y, Ezaki O (2006) Taurine (2-aminoethanesulfonic acid) deficiency creates a vicious circle promoting obesity. Endocrinology 147:3276-3284

Ulrich-Merzenich G, Zeitler H, Vetter H, Bhonde RR (2007) Protective effects of taurine on endothelial cells impaired by high glucose and oxidized low density lipoproteins. Eur J Nutr 46:431-438

Vilchis C, Salceda R (1996) Effect of diabetes on levels and uptake of putative amino acid neurotransmitters in rat retina and retinal pigment epithelium. Neurochem Res 21:1167-1171

Wang LJ, Yu YH, Zhang LG, Wang Y, Niu N, Li Q, Guo LM (2008) Taurine rescues vascular endothelial dysfunction in streptozocininduced diabetic rats: correlated with downregulation of LOX-1 and ICAM-1 expression on aortas. Eur J Pharmacol 597:75-80

Winiarska K, Szymanski K, Gorniak P, Dudziak M, Bryla J (2009) Hypoglycaemic, antioxidative and nephroprotective effects of taurine in alloxan diabetic rabbits. Biochimie 91:261-270

Wu N, Lu Y, He B, Zhang Y, Lin J, Zhao S, Zhang W, Li Y, Han P (2010) Taurine prevents free fatty acid-induced hepatic insulin 
resistance in association with inhibiting JNK1 activation and improving insulin signaling in vivo. Diabetes Res Clin Pract 90(3):288-296

Xiao C, Giacca A, Lewis GF (2008) Oral taurine but not N-acetylcysteine ameliorates NEFA-induced impairment in insulin sensitivity and beta cell function in obese and overweight, non-diabetic men. Diabetologia 51:139-146

Yamori Y, Liu L, Ikeda K, Miura A, Mizushima S, Miki T, Nara Y (2001) Distribution of twenty-four hour urinary taurine excretion and association with ischemic heart disease mortality in 24 populations of 16 countries: results from the WHO-CARDIAC study. Hypertens Res 24:453-457

Yao HT, Lin P, Chang YW, Chen CT, Chiang MT, Chang L, Kuo YC, Tsai HT, Yeh TK (2009) Effect of taurine supplementation on cytochrome P450 2E1 and oxidative stress in the liver and kidneys of rats with streptozotocin-induced diabetes. Food Chem Toxicol 47:1703-1709

Yokogoshi H, Mochizuki H, Nanami K, Hida Y, Miyachi F, Oda H (1999) Dietary taurine enhances cholesterol degradation and reduces serum and liver cholesterol concentrations in rats fed a high-cholesterol diet. J Nutr 129:1705-1712
Yu X, Xu Z, Mi M, Xu H, Zhu J, Wei N, Chen K, Zhang Q, Zeng K, Wang J et al (2008) Dietary taurine supplementation ameliorates diabetic retinopathy via anti-excitotoxicity of glutamate in streptozotocin-induced Sprague-Dawley rats. Neurochem Res 33:500-507

Zeng K, Xu H, Mi M, Zhang Q, Zhang Y, Chen K, Chen F, Zhu J, Yu $X$ (2009) Dietary taurine supplementation prevents glial alterations in retina of diabetic rats. Neurochem Res 34:244-254

Zeng K, Xu H, Mi M, Chen K, Zhu J, Yi L, Zhang T, Zhang Q, Yu X (2010a) Effects of taurine on glial cells apoptosis and taurine transporter expression in retina under diabetic conditions. Neurochem Res 35:1566-1574

Zeng K, Xu H, Chen K, Zhu J, Zhou Y, Zhang Q, Mantian M (2010b) Effects of taurine on glutamate uptake and degradation in Müller cells under diabetic conditions via antioxidant mechanism. Mol Cell Neurosci 45:192-199

Zhang C, Yang J, Jennings LK (2004) Leukocyte-derived myeloperoxidase amplifies high-glucose-induced endothelial dysfunction through interaction with high-glucose-stimulated, vascular nonleukocyte-derived reactive oxygen species. Diabetes 53:2950 2959 